\title{
Gendered Occupational Interests: Prenatal Androgen Effects on Psychological Orientation to Things Versus People
}

\author{
Adriene M. Beltz, \\ Department of Psychology, The Pennsylvania State University \\ Jane L. Swanson, and \\ Department of Psychology, Southern Illinois University Carbondale \\ Sheri A. Berenbaum \\ Departments of Psychology and Pediatrics, The Pennsylvania State University
}

\begin{abstract}
There is considerable interest in understanding women's underrepresentation in science, technology, engineering, and mathematics careers. Career choices have been shown to be driven in part by interests, and gender differences in those interests have generally been considered to result from socialization. We explored the contribution of sex hormones to career-related interests, in particular studying whether prenatal androgens affect interests through psychological orientation to Things versus People. We examined this question in individuals with congenital adrenal hyperplasia $(\mathrm{CAH})$, who have atypical exposure to androgens early in development, and their unaffected siblings (total $N=125$ aged 9 to 26 years). Females with CAH had more interest in Things versus People than did unaffected females, and variations among females with $\mathrm{CAH}$ reflected variations in their degree of androgen exposure. Results provide strong support for hormonal influences on interest in occupations characterized by working with Things versus People.
\end{abstract}

\section{Keywords}

androgens; interests; occupations; sex differences; congenital adrenal hyperplasia; STEM careers

Sex differences in occupations are a subject of intense scientific and public interest, with particular concern about women's underrepresentation in science, technology, engineering, and mathematics (STEM) careers. Many explanations of this disparity have been offered, including cultural stereotypes about what is acceptable for the sexes, situational cues that induce identity threat, social barriers that hinder women's success, and personal characteristics, such as cognitive abilities and interests (reviewed in Ceci and Williams, 2007; Halpern et al., 2007).

Particular attention has focused on interests that are stable and predict career choices, even across many years. A meta-analysis showed vocational interests to be strongly consistent

\footnotetext{
(C) 2010 Elsevier Inc. All rights reserved.

Correspondence concerning this article should be addressed to Sheri A. Berenbaum, Department of Psychology, 519 Moore Building, The Pennsylvania State University, University Park, PA 16802. sab31@ psu.edu.

Publisher's Disclaimer: This is a PDF file of an unedited manuscript that has been accepted for publication. As a service to our customers we are providing this early version of the manuscript. The manuscript will undergo copyediting, typesetting, and review of the resulting proof before it is published in its final citable form. Please note that during the production process errors may be discovered which could affect the content, and all legal disclaimers that apply to the journal pertain.
} 
from early adolescence to middle adulthood (Low et al., 2005). In fact, vocational interests in high school and college have been shown to predict occupations up to 30 years later (Hansen, 2005; Rottinghaus et al., 2007).

Gender differences in occupational interests have generally been considered to result from socialization (Eccles, 1994). For example, children's occupational interests and career choices are linked to their parents' expectations: Parents' gender-typed occupational expectations for their 15-year-old children predicted children's gender-typed occupational expectations two years later; moreover, parents' expectations about gender-typed occupations for their children at age 17 predicted the children's actual career choices at age 28 (Jacobs et al., 2006). Further, situational cues may affect interest in STEM careers through social identity threat (Murphy et al., 2007).

Gendered occupational interests are also influenced by sex-related biological factors, particularly sex hormones such as androgens. These hormones are present early in development and organize the brain, as studies in nonhuman animals show (Wallen, 2009). In people, prenatal androgen levels and gender socialization are typically confounded, but their effects can be disentangled in females with congenital adrenal hyperplasia (CAH), who are exposed to higher than normal (sex-atypical) prenatal androgen levels but who are reared and identify as female.

Consistent with hormone effects on interests, females with $\mathrm{CAH}$ are considerably more interested than are females without $\mathrm{CAH}$ in male-typed toys, leisure activities, and occupations, from childhood through adulthood (reviewed in Blakemore et al., 2009; CohenBendahan et al., 2005); adult females with $\mathrm{CAH}$ also engage more in male-typed occupations than do females without CAH (Frisén et al., 2009). Male-typed interests of females with $\mathrm{CAH}$ are associated with degree of androgen exposure, which can be inferred from genotype or disease characteristics (Berenbaum et al., 2000; Meyer-Bahlburg et al., 2006; Nordenström et al., 2002). Interests of males with CAH are similar to those of males without CAH because both are exposed to high (sex-typical) prenatal androgens and are reared as boys.

Females with $\mathrm{CAH}$ do not provide a perfect test of androgen effects on gendered characteristics because they differ from females without CAH in other ways; most notably they have masculinized genitalia that might affect their socialization. But, there is no evidence that parents treat girls with $\mathrm{CAH}$ in a more masculine or less feminine way than they treat girls without CAH (Nordenström et al., 2002; Pasterski et al., 2005). Further, some findings from females with $\mathrm{CAH}$ have been confirmed in typical individuals whose postnatal behavior has been associated with prenatal hormone levels measured in amniotic fluid. Amniotic testosterone levels were found to correlate positively with parent-reported male-typed play in girls and boys at ages 6 to 10 years (Auyeung et al., 2009).

The psychological mechanism through which androgen affects interests has not been wellinvestigated, but there is some consensus that sex differences in interests reflect an orientation toward people versus things (Diekman et al., 2010) or similar constructs, such as organic versus inorganic objects (Benbow et al., 2000). The Things-People distinction is, in fact, the major conceptual dimension underlying the measurement of the most widely-used model of occupational interests (Holland, 1973; Prediger, 1982); it has also been used to represent leisure interests (Kerby and Ragan, 2002) and personality (Lippa, 1998). For example, occupational interests measured by the Strong Interest Inventory (Harmon et al., 1994) are classified into six dimensions (Realistic, Investigative, Artistic, Social, Enterprising, Conventional, RIASEC), that form two higher-order, orthogonal, bipolar factors, Things-People and Data-Ideas. The Things-People factor displays a large sex 
difference, $d=.93$, whereas the Data-Ideas factor does not, $d=-.10$ (Su et al., 2009). Boys and men prefer occupations related to objects (e.g., auto mechanic, chemist), whereas girls and women prefer occupations involving work with people (e.g., day care worker, art teacher).

In this study we tested whether prenatal androgen effects on occupational interests reflect the underlying psychological dimension of things versus people. Specifically, we hypothesized that females with $\mathrm{CAH}$ would have masculinized occupational interests, and thus, compared to unaffected females, would have more interest in Things-People. Moreover, scores of females with $\mathrm{CAH}$ on interest in Things-People were hypothesized to be correlated with their degree of prenatal androgen exposure.

\section{Method}

\section{Participants}

Females and males with congenital adrenal hyperplasia (CAH) due to 21-hydroxylase deficiency were studied as part of an ongoing project on androgen effects on psychological development. They were recruited through university-affiliated pediatric endocrinology clinics in the Midwestern United States, and compared to their unaffected siblings. Occupational interests were assessed in 125 individuals: 46 females with CAH, 21 unaffected sisters, 27 males with $\mathrm{CAH}$, and 31 unaffected brothers. Participants aged from 9 to 26 years $(M=16.0, S D=4.5)$; groups did not differ in age, $F(3,121)=.65, p>.05$. Because not all participants with CAH had a same-sex sibling, siblings of males and females with $\mathrm{CAH}$ were combined to form control groups. Participants represented a variety of socioeconomic backgrounds and most were Caucasian. Other findings from the larger study are summarized elsewhere (e.g., Blakemore et al., 2009). The main hypotheses concerned females, but males were also tested to examine specificity of findings.

Degree of prenatal androgen exposure was indexed by two features of the disease (Speiser, 2001), rated from medical records (see Berenbaum et al., 2000 for details). (1) Type of CAH was classified from least to most severe (Speiser, 2001): nonclassical (NC), simple virilizing (SV), mild salt-wasting (SW), and severe SW. SW-CAH required elevated plasma renin activity for age and responsiveness to mineralocorticoid therapy. Classification as mild SW$\mathrm{CAH}$ required that all measurements of serum sodium be at least $129 \mathrm{mmol} / \mathrm{L}$, and that there be no episodes of hypotension or shock; classification as severe SW-CAH required that serum sodium in the neonatal period be less than $129 \mathrm{mmol} / \mathrm{L}$, or that there be at least one episode of hypotension or shock. Information on disease type was available for 43 of 46 females with CAH ( $6 \mathrm{NC}, 5 \mathrm{SV}, 10$ mild SW, 22 severe SW) and all 27 males with CAH (5 NC, 1 SV, 5 mild SW, 16 severe SW). (2) Genital virilization at birth was rated on the Prader scale (Prader, 1954), which ranges from 0 (typical female genitalia) through 6 (typical male genitalia). This information was available for 37 of 46 females with $\mathrm{CAH}$; scores ranged from 0 to $4(M=2.4, S D=1.5)$. The two indices of prenatal androgen exposure (CAH type and Prader rating) were significantly related for females with $\mathrm{CAH}$, $r(37)=.73, p<.01$.

\section{Measures and Procedure}

The Occupational Interests Inventory (OII) was developed for this study because standard instruments are intended only for older adolescents and adults. The OII parallels the Strong Interest Inventory (Harmon et al., 1994) and measures the same dimensions (Realistic, Investigative, Artistic, Social, Enterprising, Conventional, RIASEC) in participants of a wide age range. Participants rated their interest in each of 64 jobs by indicating whether they would dislike (0), be indifferent to (1), or like (2) doing that type of work. 
A composite score was created for each RIASEC dimension by averaging items representing that dimension (see Table 1), excluding 17 items endorsed by less than $10 \%$ of the sample; high scores indicate high interest. The Conventional dimension was excluded because it had few items and low reliability, consistent with other findings (Lippa, 1998). The remaining five RIASEC scores were internally consistent (see Table 1).

\section{Results}

Descriptive data and group comparisons (from independent samples $t$-tests) for the five RIASEC composite scores are presented in Table 2. There were large sex differences in four of the five RIASEC dimensions examined: Unaffected females reported more interest in Artistic, Social, and Enterprising occupations than did unaffected males, whereas unaffected males reported more interest in Realistic occupations than did unaffected females. Females with CAH also reported more interest in Realistic and Investigative occupations than did unaffected females; differences were moderate in size. Males with CAH and unaffected males did not differ significantly on any of the five RIASEC dimensions.

The validity of the OII for assessing the Things-People distinction was determined by correcting the five RIASEC composite scores for overall response set (tendency to endorse items) and then conducting a principal components analysis with varimax rotation to extract two components (Lippa, 1998). Response set correction involved subtracting a participant's average response (mean of five RIASEC composite scores) from each composite score. Groups did not differ in response set, $F(3,121)=1.29, p>.05$. The five RIASEC dimensions defined the two expected components that could be labeled Things-People and Data-Ideas; Figure 1 shows the location of the dimensions in two-component space. The only anomaly was the Artistic dimension: it loaded on Data more than Ideas, perhaps reflecting the meaning of "art" for children versus adults. The Artistic dimension was appropriately represented on Things-People.

The Things-People component score was used for subsequent analyses; higher scores represent a predominance of interest in Things, and lower scores a greater interest in People. The Data-Ideas component was not considered further because it shows no sex difference.

Androgen effects on interests were examined by comparing groups on Things-People using a two-way analysis of variance (ANOVA), with factors of sex (male, female) and condition (CAH, unaffected). The primary hypothesis was tested in the interaction between sex and condition, which was expected to result from a specific pattern of group means reflecting interest in Things relative to People: unaffected females $<$ females with $\mathrm{CAH}<$ males with $\mathrm{CAH}=$ unaffected males.

Results supported our hypotheses, as shown in Table 3. There was a significant sex difference (females had lower scores than males), $F(1,121)=47.16, p<.001$, partial $\eta^{2}=$. 28 , no significant effect of condition, $F(1,121)=2.49, p>.05$, partial $\eta^{2}=.02$, and a significant interaction between sex and condition, $F(1,121)=5.51, p<.05$, partial $\eta^{2}=.04$. The interaction was probed with $t$-tests using Type I error of .01 to correct for multiple comparisons. Statistical test results and $d$ 's are shown in Table 3. Interest in Things relative to People was higher in females with CAH than in unaffected females, and lower than in males (CAH and unaffected). Unaffected females showed less interest in Things relative to People than males. Males with and without $\mathrm{CAH}$ were not significantly different. There were no between-group differences in variability $(p>.05$ for all Levene's equality of variance tests).

There was considerable within-group variability, as shown in Figure 2. We examined whether variability among individuals with $\mathrm{CAH}$ was related to degree of prenatal androgen 
exposure. Among females with CAH, scores on Things-People were positively correlated with degree of androgen exposure, reflected in both degree of genital virilization, $r(37)=$. $39, p<.01$, and CAH type, $r(43)=.34, p<.05$. Females with severe SW-CAH had higher scores on Things-People $(M=.16, S D=.83)$ than females with other forms of CAH: mild $\mathrm{SW}(M=-.81, S D=.85), \mathrm{SV}(M=-.85, S D=1.17)$, and NC $(M=-.46, S D=.43)$. Among males with $\mathrm{CAH}$, scores on Things-People were not significantly correlated with $\mathrm{CAH}$ type, $r(27)=-.07, p>.05$.

\section{Discussion}

The results support the hypothesis that sex differences in occupational interests are due, in part, to prenatal androgen influences on differential orientation to objects versus people. Compared to unaffected females, females with CAH reported more interest in occupations related to Things versus People, and relative positioning on this interest dimension was substantially related to amount of prenatal androgen exposure. Females with $\mathrm{CAH}$ scored in between males and typical females on the Things-People dimension; their intermediate score might reflect a dose effect of prenatal androgen or the feminizing effects of socialization or other biological factors related to XX karyotype.

These findings extend previous work by identifying an underlying psychological dimension - interest in engaging with objects versus people - for prenatal androgen effects on leisure and occupational interests (Berenbaum, 1999; Meyer-Bahlburg et al., 2006). This work is relevant to the broad question of women's underrepresentation in STEM careers because it points to a hormonally-influenced psychological characteristic - interest in working with objects versus people - that underlies vocational interests. Those interests are important because they predict career choices (Hansen, 2005; Rottinghaus et al., 2007). Our results suggest that typical women, who are exposed to low levels of prenatal androgen, participate less than do men in STEM careers partly because they are interested in working with people. This is consistent with evidence that women value communal goals, which are perceived to be at odds with STEM careers (Diekman et al., 2010) and that women who enter STEM careers often do so in people-oriented professions, such as medicine (Benbow et al., 2000).

There are several methodological issues to consider in interpreting the results. First, $\mathrm{CAH}$ is not a perfect experiment; females with CAH differ from unaffected siblings in ways other than prenatal androgen. Nevertheless, prenatal androgen is the most likely explanation for the results because there was a high correlation between degree of prenatal androgen exposure and occupational interest, and males with CAH did not differ from unaffected males; further, androgen effects on interests have been confirmed in typical samples (Auyeung et al., 2009). Second, our sample was not racially or ethnically diverse. However, the structure of interests is invariant across ethnic groups (Gupta et al., 2008). Third, the measure we used was developed specifically for this study. But it is based upon the RIASEC theoretical framework, generally conformed to the expected higher-order structure, and Things-People showed the expected sex difference (Su et al., 2009).

An important issue concerns the bipolarity of Things-People. Although analyses generally produce a bipolar factor, it is important to consider the possibility that there are two separate dimensions - Things and People. This parallels discussions of the dimensionality of gendertyping, with the original conceptualization of a bipolar dimension of masculinity-femininity refined to acknowledge the separability of masculinity and femininity (Bem, 1975). The bipolar structure of Things-People is maintained by standard analyses that include correction for response set and varimax rotation in factor analyses. Our sample was not large enough to determine whether occupational interests were better described by two separate factors than by a single bipolar factor. 
Nevertheless, some insight into the nature of Things-People is provided by an examination of group means for the Realistic and Social dimensions which anchor theoretically (Prediger, 1982) and empirically (Figure 1) the poles of Things and People, respectively. As shown in Table 2, the pattern of findings on Realistic and Social composite scores for unaffected males and females is consistent with an interpretation of Things-People as a bipolar dimension: Males were interested in Realistic but not Social occupations whereas females were interested in Social but not Realistic occupations. The pattern of findings for females with $\mathrm{CAH}$, however, might be easier to interpret with two separate dimensions (Things and People) rather than a bipolar one. Females with CAH reported similar interest in Realistic and Social occupations, resulting in a score on the Things-People component that is close to 0, which should not be interpreted as a lack of occupational interests. Moreover, compared to unaffected females, females with CAH were as interested in Social occupations but more interested in Realistic occupations (although not as interested as unaffected males). This suggests that the scores of females with CAH on Things-People reflect an increased interest in Things-related occupations and not a decreased interest in People-related occupations.

Our findings indicate that career choices are influenced by prenatal androgens through a psychological orientation to objects versus people that manifests in gender-typed occupational interests. We emphasize, however, the complexity of career choices: Occupational interests are not determined exclusively by sex or prenatal androgen exposure, as seen in the overlapping scores of our groups, and in other data showing parent socialization of occupational interests (Eccles, 1994); moreover, interests are only one contributor to career choice (Ceci and Williams, 2007; Halpern et al., 2007). In combination with other findings on gendered interests, our results are relevant to efforts to increase participation of girls and women in STEM careers. It is important to recognize that career choices have roots in early-developing and biologically-influenced interests. Girls and women might be encouraged to pursue STEM careers by focusing on the ways in which an orientation to people is compatible with those careers.

\section{Research Highlights}

- $\quad$ Sex-typed interests partly underlie women's underrepresentation in STEM careers

- $\quad$ Sex-typed career interests are influenced by prenatal androgens

- $\quad$ Sex-typed career interests reflect orientation to objects (vs. people)

- $\quad$ Females with $\mathrm{CAH}$ are more likely than controls to prefer careers related to objects

- $\quad$ Prenatal androgens affect interests through orientation to Things vs. People

\section{Acknowledgments}

This research was supported in part by National Institutes of Health Grant HD19644. We thank the following people who contributed to this work: Kristina Bryk coordinated the project that produced these data and assisted with manuscript preparation; Stephen Duck coded medical records; he and Deborah Edidin, Erica Eugster, Reema Habiby, David Klein, Bernard Silverman, Kumud Sane, Neil White, and David Wyatt generously provided access to their patients; Lori Alegnani collected and processed data; graduate and undergraduate research assistants processed data; Judith Elaine Owen Blakemore, Theresa Vescio, Norman Henderson, and two anonymous reviewers provided helpful comments on the manuscript. We are particularly grateful to the patients and their families for their participation in the study. 


\section{References}

Auyeung B, Baron-Cohen S, Ashwin E, Knickmeyer R, Taylor K, Hackett G, Hines M. Fetal testosterone predicts sexually differentiated childhood behavior in girls and in boys. Psych. Sci. 2009; 20:144-148.

Bem SL. Sex role adaptability: One consequence of psychological androgyny. J. Pers. Soc. Psychol. 1975; 31:634-643.

Benbow CP, Lubinski D, Shea DL, Eftekhari-Sanjani H. Sex differences in mathematical reasoning ability at age 13: Their status 20 years later. Psych. Sci. 2000; 11:474-480.

Berenbaum SA. Effects of early androgens on sex-typed activities and interests in adolescents with congenital adrenal hyperplasia. Horm. Behav. 1999; 35:102-110. [PubMed: 10049608]

Berenbaum SA, Duck SC, Bryk K. Behavioral effects of prenatal versus postnatal androgen excess in children with 21-hydroxylase-deficient congenital adrenal hyperplasia. J. Clin. Endocrinol. Metab. 2000; 85:727-733. [PubMed: 10690883]

Blakemore, JEO.; Berenbaum, SA.; Liben, LS. Gender development. New York: Psychology Press/ Taylor \& Francis; 2009.

Ceci, SJ.; Williams, WM. Top researchers debate the evidence. Washington, DC: American Psychological Association; 2007. Why aren't more women in science?.

Cohen-Bendahan CCC, van de Beek C, Berenbaum SA. Prenatal sex hormone effects on child and adult sex-typed behavior: Methods and findings. Neurosci. Biobehav. Rev. 2005; 29:353-384. [PubMed: 15811504]

Diekman AB, Brown ER, Johnston AM, Clark EK. Seeking congruity between goals and roles: A new look at why women opt out of science, technology, engineering, and mathematics careers. Psych. Sci. 2010; 21:1051-1057.

Eccles JS. Understanding women's educational and occupational choices: Applying the Eccles et al. model of achievement-related choices. Psychol. Women Q. 1994; 18:585-609.

Frisén L, Nordenström A, Falhammar H, Filipsson H, Holmdahl G, Janson PO, Thoren M, Hagenfeldt K, Moller A, Nordenskjold A. Gender role behavior, sexuality, and psychosocial adaptation in women with congenital adrenal hyperplasia due to CYP21A2 deficiency. J. Clin. Endocrinol. Metab. 2009; 94:3432-3439. [PubMed: 19567521]

Gupta S, Tracey TJG, Gore PA Jr. Structural examination of RIASEC scales in high school students: Variation across ethnicity and method. J. Vocat. Behav. 2008; 72:1-13.

Halpern DF, Benbow CP, Geary DC, Gur RC, Hyde JS, Gernsbacher MA. The science of sex differences in science and mathematics. Psychol. Sci. Pub. Int. 2007; 8:1-51.

Hansen, JC. Assessment of interests. In: Brown, SD.; Lent, RW., editors. Career development and counseling: Putting theory and research to work. Hoboken, NJ: Wiley; 2005. p. 281-304.

Harmon, LW.; Hansen, JC.; Borgen, FH.; Hammer, AL. Strong Interest Inventory applications and technical guide. Stanford, CA: Stanford University Press; 1994.

Holland, JL. Making vocational choices: A theory of careers. Englewood Cliffs, NJ: Prentice Hall; 1973.

Jacobs JE, Chhin CS, Bleeker MM. Enduring links: Parents' expectations and their young adult children's gender-typed occupational choices. Educ. Res. Eval. 2006; 12:395-407.

Kerby DS, Ragan KM. Activity interests and Holland's RIASEC system in older adults. Int. J. Aging Hum. Dev. 2002; 55:117-139. [PubMed: 12513035]

Lippa R. Gender-related individual differences and the structure of vocational interests: The importance of the people-things dimension. J. Pers. Soc. Psychol. 1998; 74:996-1009. [PubMed: 9569655]

Low KSD, Yoon M, Roberts BW, Rounds J. The stability of vocational interests from early adolescence to middle adulthood: A quantitative review of longitudinal studies. Psychol. Bull. 2005; 131:713-737. [PubMed: 16187855]

Meyer-Bahlburg HFL, Dolezal C, Baker SW, Ehrhardt AA, New MI. Gender development in women with congenital adrenal hyperplasia as a function of disorder severity. Arch. Sex. Behav. 2006; 35:667-684. [PubMed: 16902816] 
Murphy MC, Steele CM, Gross JJ. Signaling threat: How situational cues affect women in math, science, and engineering settings. Psych. Sci. 2007; 18:879-885.

Nordenström A, Servin A, Bohlin G, Larsson A, Wedell A. Sex-typed toy play behavior correlates with the degree of prenatal androgen exposure assessed by CYP21 genotype in girls with congenital adrenal hyperplasia. J. Clin. Endocrinol. Metab. 2002; 87:5119-5124. [PubMed: 12414881]

Pasterski VL, Geffner ME, Brain C, Hindmarsh P, Brook C, Hines M. Prenatal hormones and postnatal socialization by parents as determinants of male-typical toy play in girls with congenital adrenal hyperplasia. Child Dev. 2005; 76:264-278. [PubMed: 15693771]

Prader A. Der genitalbefund beim pseudohermaphroditismus femininus des kongenitalen androgenitalen syndroms. Helvetica Paediatr. Acta. 1954; 9:231-248.

Prediger DJ. Dimensions underlying Holland's hexagon: Missing link between interests and occupations? J. Vocat. Behav. 1982; 21:259-287.

Rottinghaus PJ, Coon KL, Gaffey AR, Zytowski DG. Thirty-year stability and predictive validity of vocational interests. J. Career Assess. 2007; 15:5-22.

Speiser PW. Congenital adrenal hyperplasia owing to 21-hydroxylase deficiency. Endocrinol. Metab. Clin. N. Am. 2001; 30:31-59.

Su R, Rounds J, Armstrong PI. Men and things, women and people: A meta-analysis of sex differences in interests. Psychol. Bull. 2009; 135:859-884. [PubMed: 19883140]

Wallen K. The Organizational Hypothesis: Reflections on the 50th anniversary of the publication of Phoenix, Goy, Gerall, and Young (1959). Horm. Behav. 2009; 55:561-565. [PubMed: 19446072] 


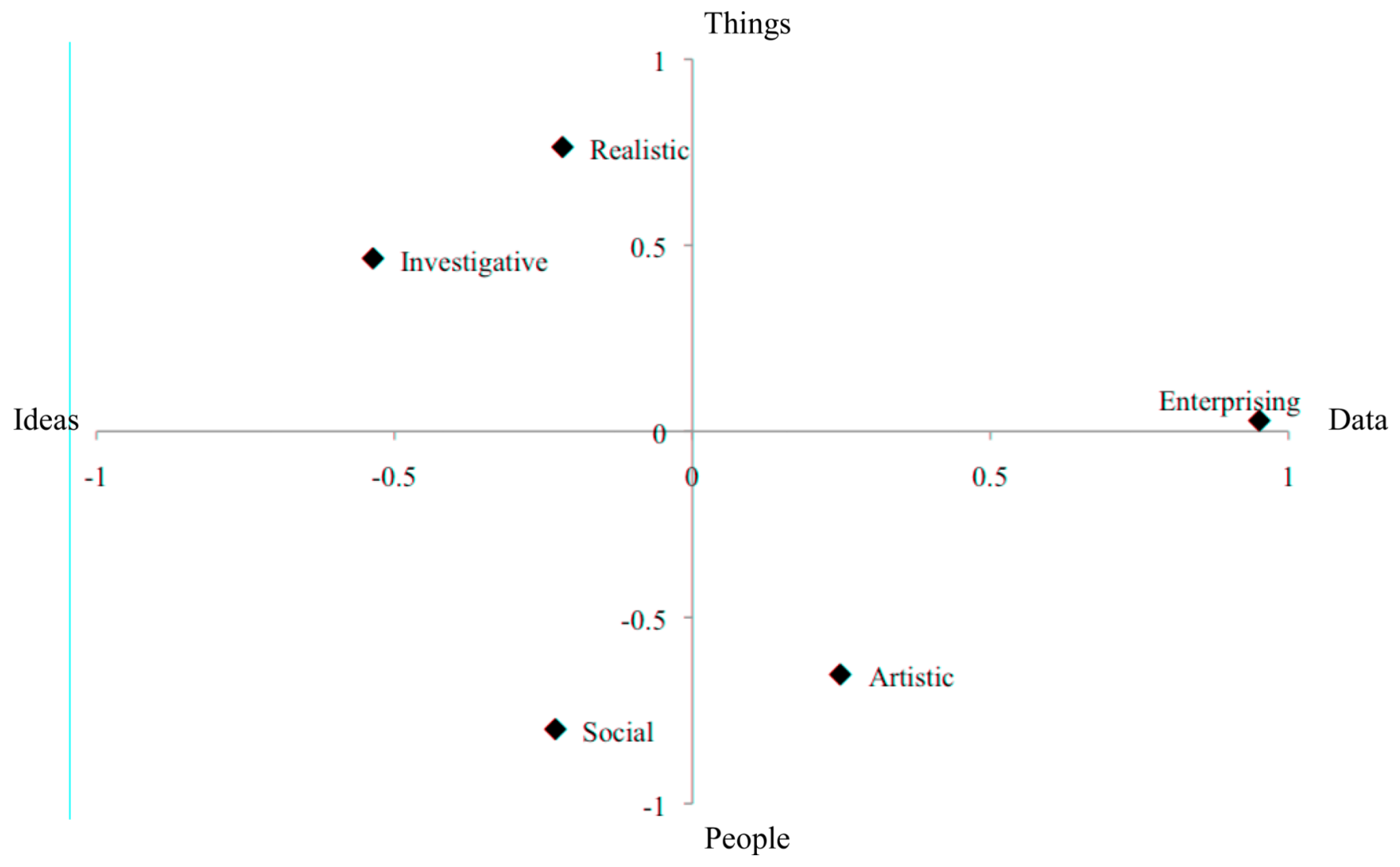

Figure 1.

Five RIASEC dimensions plotted according to their loadings on two extracted and rotated orthogonal components, Things-People and Data-Ideas. 


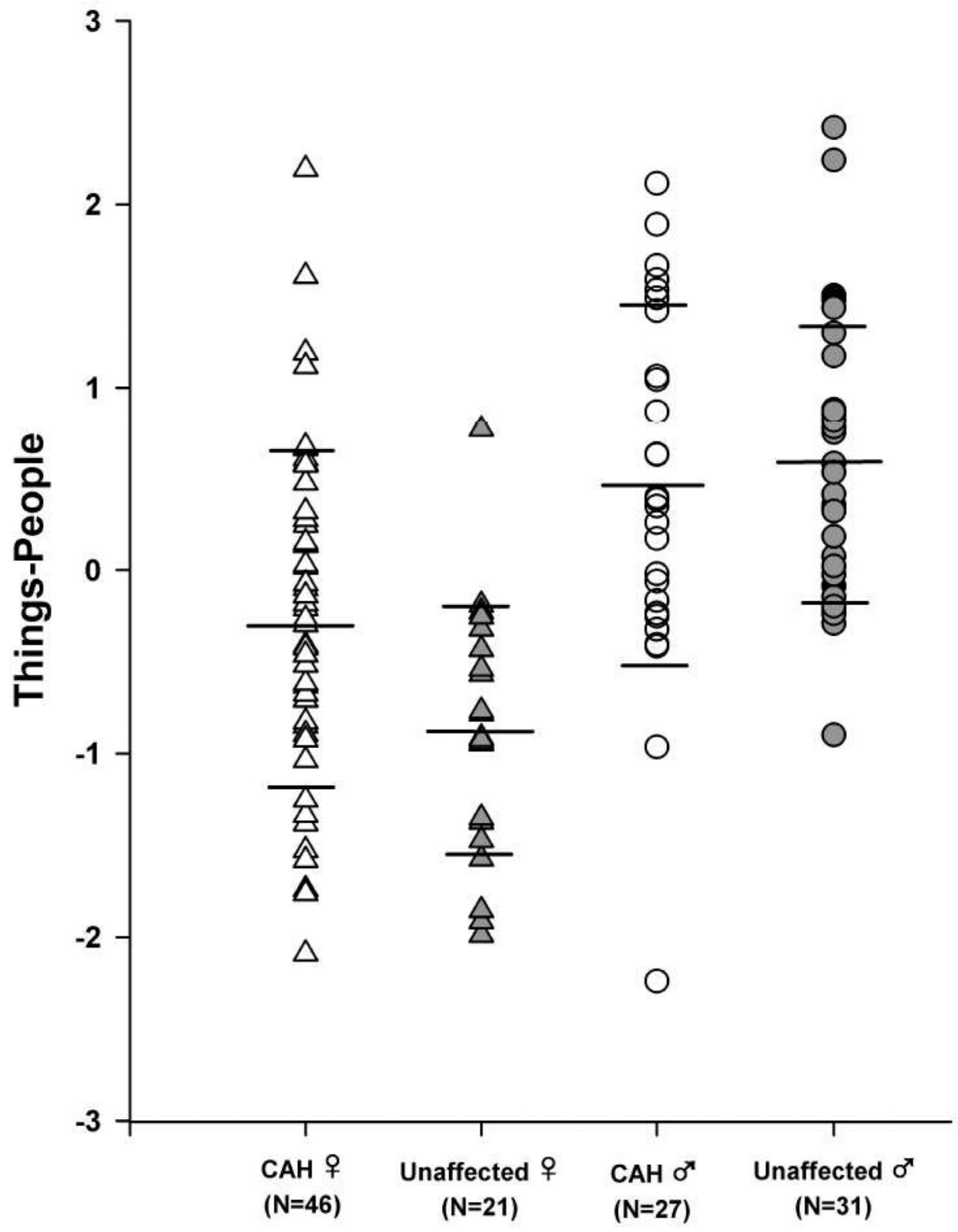

Figure 2.

Scores of individual participants on the Things versus People component plotted by group. Males are represented by circles and females by triangles; open shapes indicate individuals with $\mathrm{CAH}$, gray shapes indicate unaffected individuals. Horizontal lines represent group means and standard deviations. 


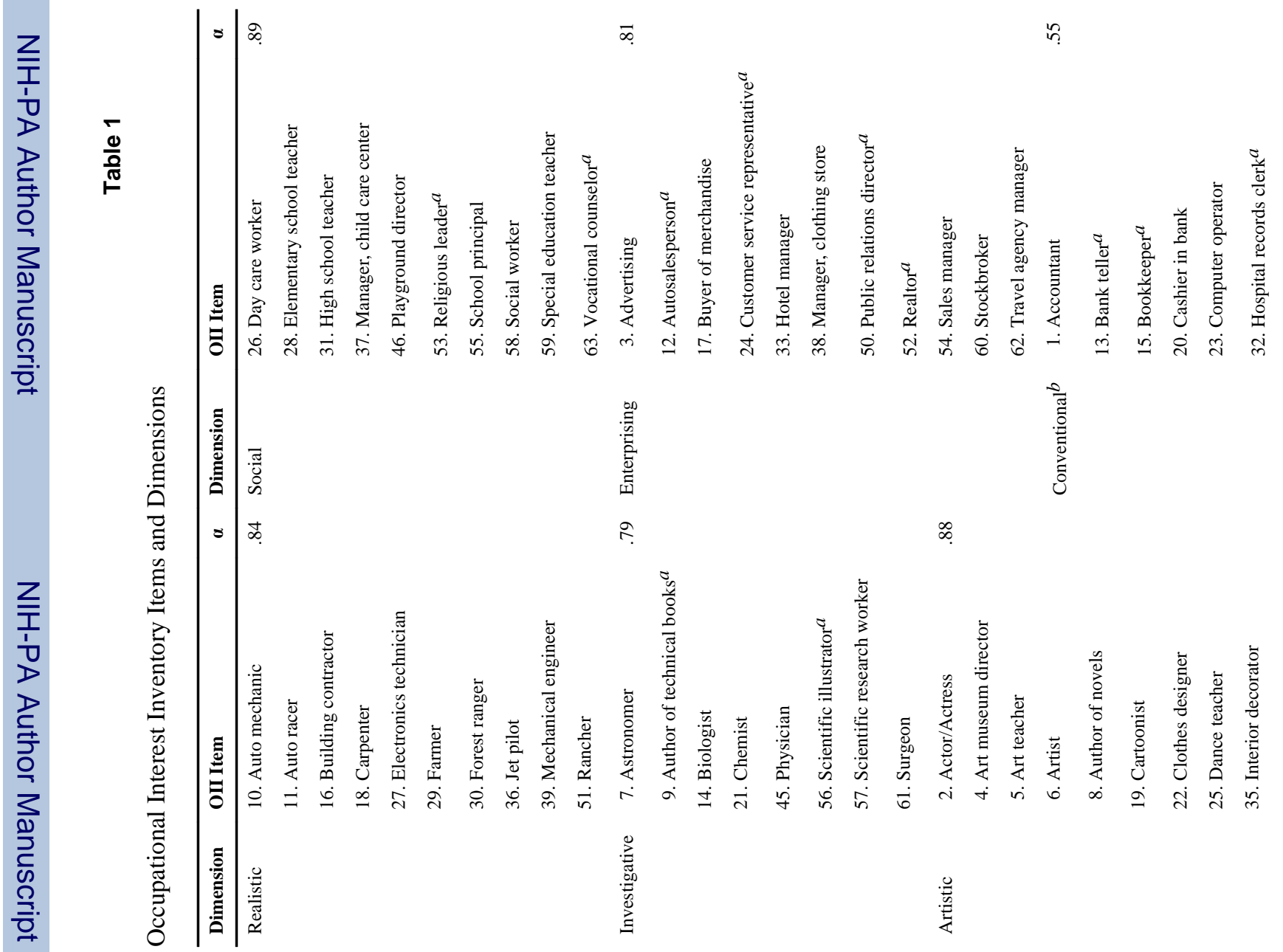
Horm Behav. Author manuscript; available in PMC 2012 September 1. 


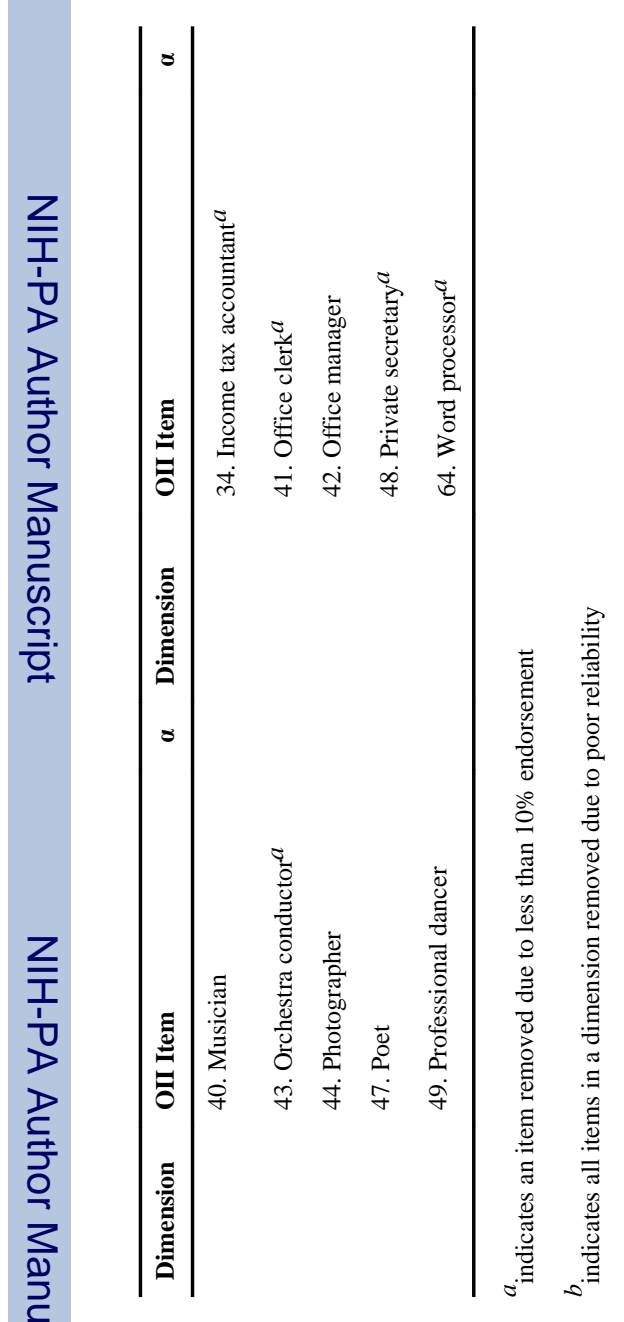




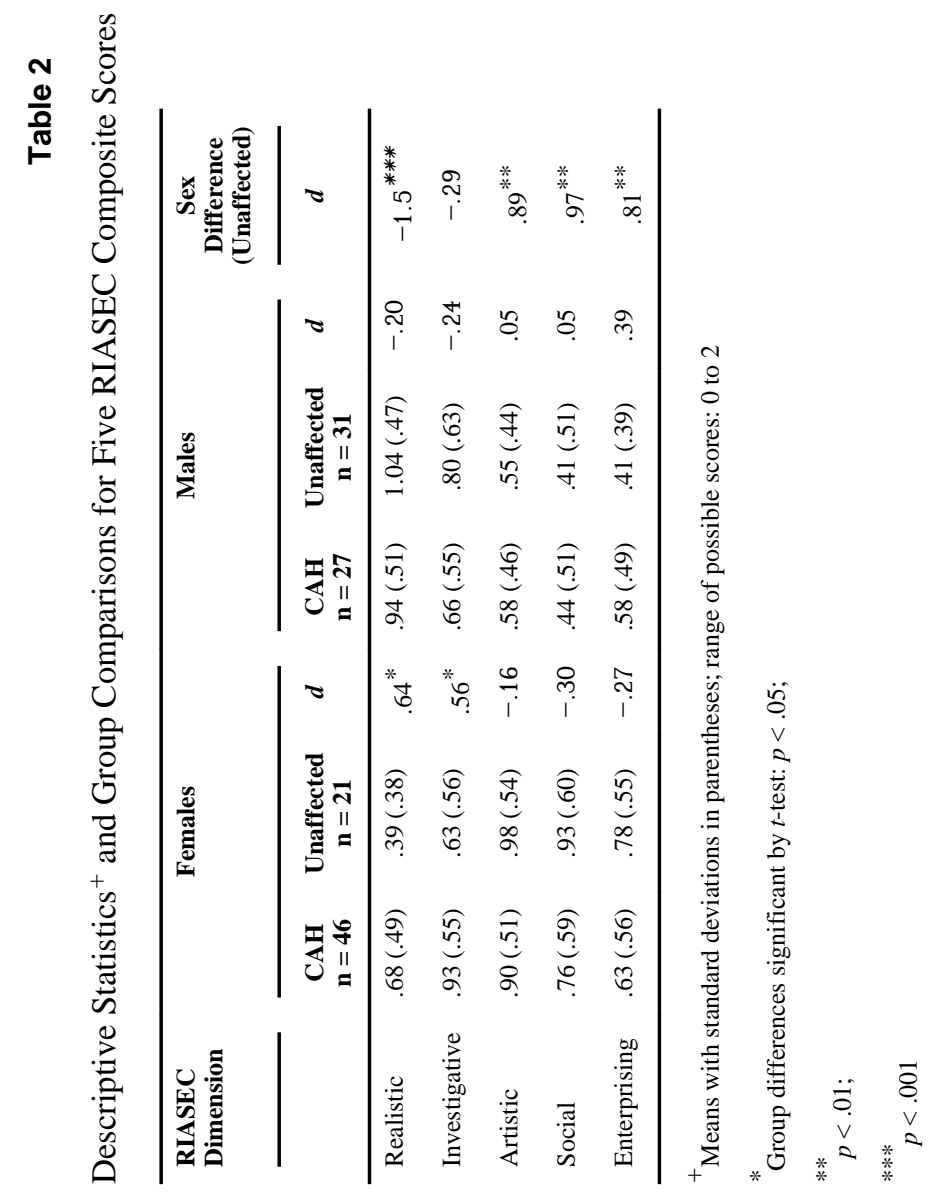




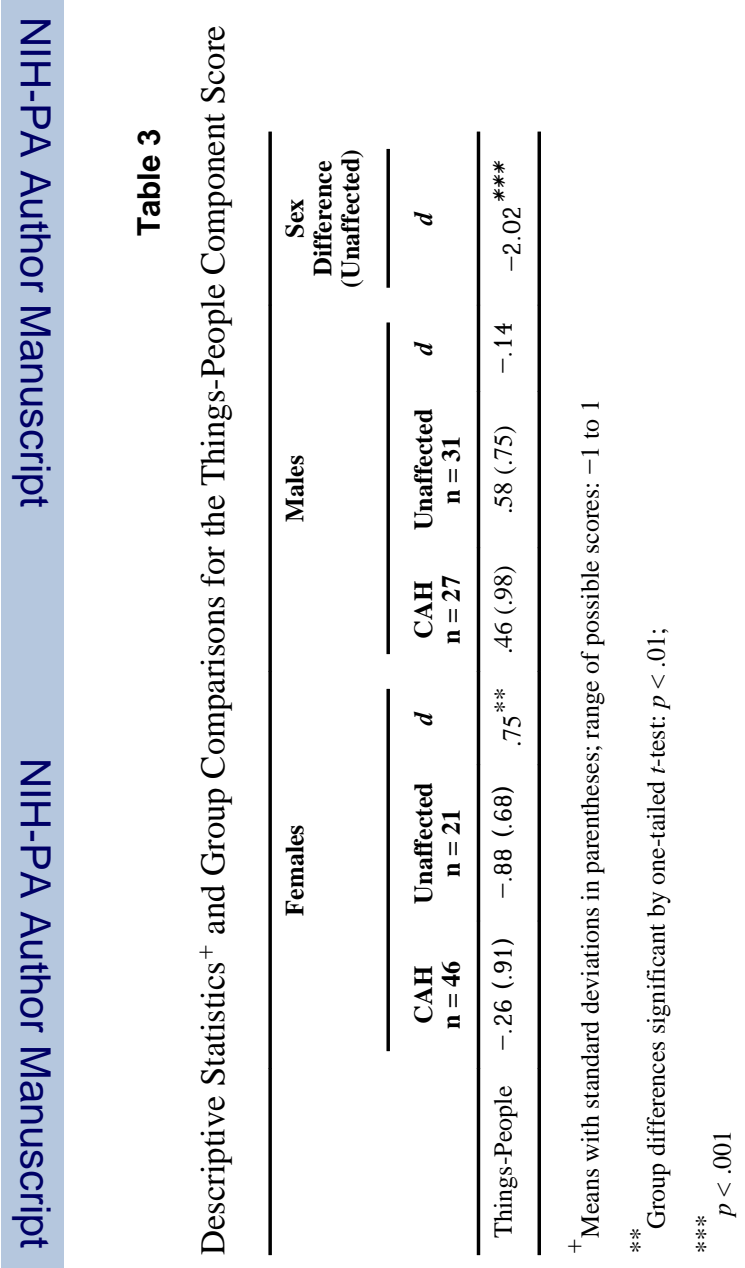

Horm Behav. Author manuscript; available in PMC 2012 September 1. 